\title{
Financial Leading Indicators of Banking Distress: A Micro Prudential Approach - Evidence from Europe
}

\author{
Ahlem Selma Messai ${ }^{1} \&$ Mohamed Imen Gallali ${ }^{1}$ \\ ${ }^{1}$ High Business School of Tunis, Manouba University, Tunisia \\ Correspondence: Ahlem Selma Messai, High business School of Tunis, Manouba University, 2010 Manouba, \\ Tunisia. Tel: 216-25-16-0565. E-mail: asm_j@hotmail.fr
}

Received: February 20, 2015 Accepted: April 14, 2015 Online Published: July 6, 2015

doi:10.5539/ass.v11n21p78 URL: http://dx.doi.org/10.5539/ass.v11n21p78

\begin{abstract}
Sovereign and Subprime crises have corrosive effects on European banking system. In this study, we aim to explain and predict the state of distress for 618 European banks for a five year period (2007-2011). For this purpose, we applied early warning systems using traditional and developed methods: discriminant analysis, logistic regression and the artificial intelligence. Those methods aim to predict bank distress up to a year (two years) before it actually happened. Our study seeks to compare between these three methods and to choose the most appropriate for prediction. The key finding of this study demonstrates that the neural network method outperforms the other models. This result is too much useful for banks and help policy makers to do a better job in terms of regulatory reforms.
\end{abstract}

Keywords: a microprudential approach, bank distress, non performing loans, financial soundness indicators

\section{Introduction}

Given the importance of predicting bank distress, this topic has been gaining a greater interest in the two last decades. In fact, the main objective of an early warning model is forecasting difficulties in financial institutions. These early warning systems have recently experienced a very rapid evolution, particularly in view of banking regulators who continually develop such models in order to identify the financial distress in banks and provide an advance alarm to distressed institutions, allowing them the sufficient time to avoid the emergence of potential crises. Then, banks could react and take the necessary corrective measures. Moreover, early warning models identify three types of crises: currency crises, debt crises, and also banking crises. The authorities implement macroprudential supervision standards that attempt to assess the soundness of the financial system and its vulnerability to potential shocks. The quantitative analysis used in macroprudential supervision complements the use of financial soundness indicators (FSIs) and also the implementation of stress tests. Financial soundness indicators (FSI) were established by the FMI in order to gauge the financial vulnerability in banks. The FSI were grouped into two main cores: the core set indicators and the encouraged indicators. The macroprudential supervision approach that uses a combination of qualitative and quantitative methods. The qualitative methods focus on the quality of the legal, regulatory framework and the governance mechanism in the financial sector.

An important part of the qualitative information is often collected and used by internationally recognized standards and codes of good practice. However, the quantitative methods include a combination of indicators and statistical techniques able to summarize the strength and the resilience of the financial system to vulnerabilities.

Thus, these various tools are mapping all the possible financial vulnerabilities that could appear in different economic industries. Mager and Shmeider (2009) argue that these financial soundness indicators are indeed used in order to test the soundness of the banks and the financial system as a whole using a micro stress testing framework (Qualiariello, 2009; Lelyveld, 2009). In this case, several techniques have been used to predict the distress of a credit institution and also to help regulators in taking the right preventive actions. Among these techniques, we could mention linear regression or discriminant analysis and logistic regression (logit or probit). Moreover, we should notice that in recent years, several studies have focused on techniques that use artificial intelligence such as the neural network method.

In fact, these studies have also demonstrated the effectiveness of the new artificial neural methods compared to other techniques. These new techniques are used in several areas. However, they are recently used in order to predict the failure of a financial system. 
Our study aims to predict the difficulties faced by 618 European banks and also to determine the most relevant indicators of a bank distress. This paper is also based on three methods in order to compare the effectiveness of different methods. The purpose of our work is to find the best method to forecast bank distress in a microprudential framework. In addition, our study tries to decompose the relevant determinants of internal failure affecting especially the solvency of banks that could lead the regulator to act before a bank's distress.

First, the introduction has to be seen within the wider context of existing frameworks in this field. The remainder of this paper is organized as follows. Section two develops a brief review of different methods of forecasting difficulties faced by banks and methods integrating financial soundness indicators. Section three describes the research design. Section four analyzes and summarizes the empirical findings. Finally, section five presents the conclusion, limitations and future researches.

\section{Related Studies}

This study is related to a growing body of literature that analyses the banking distress. Financial soundness indicators were established by the International Monetary Fund to ensure the soundness of financial institutions and markets as well as companies (Kulthunga \& Rehman 2012). Financial soundness indicators are summarized by CAMELS criteria (C: capital adequacy; A: asset quality; M: management quality; E: earnings ability; L: liquidity; S: Sensitivity to market..). In addition, according to some authors, other accounting measures do not contain additional information to those provided by CAMELS indicators (Akhter \& Dali, 2009). In addition, according to the World Bank (2005), these indicators (CAMELS) are a complement to the existing macro-prudential tools. These tools used by international organizations (FMI, ECB, WB...) in order to assess the risk management. In other words, they are complementary to the early warning systems in predicting distress. The most important difference between these two methods: early warning systems detect distress for individual institutions when the macro stress tests seek distress for a banking system.

In this study, we try to show that financial soundness indicators (FSI) assess and predict the financial sector vulnerability. Cihak (2007) argues that financial ratios are able enough to provide a summary Table of the soundness in a financial sector and in its different components. Cardarelli, Elekdag and Lall, (2011) discuss the reasons of the severe financial turbulence which could lead effectively to an economic slowdown. In addition to that, Authors identified the different phases of the financial turmoil in advanced economies using a financial stress index (FSI), and proposed an analytical framework able to assess the impact of financial stress on the real economy. They conclude that the financial turmoil characterized by bank distress is more likely to undergo a deep downturn. Several models have been developed in order to detect distress and weaknesses in financial institutions. As a matter of fact, these models are widely used to ensure financial system stability. In particular, developed models are respectively the early warning systems (EWS), the resilience tests (stress tests) and finally artificial intelligence models which were recently implemented. Indeed, some authors have emphasized the complementarity between stress tests and early warning systems.

Early warning systems include different ratios derived from financial statements which include variables related to the regulatory and institutional environment, they even use different macroeconomic variables with the aim to predict system's failures.

In addition to that, those monitoring systems are also used to provide useful indicators of the bank situation. These systems are used primarily to get prevented from bank problems. Banking system problems are often presented by a weak level of capitalization, liquidity and solvency... For this reason, often studies used several indicators relating to solvency, performance and liquidity to assess the risk profile of a banking group (Anderson, 2008; Giovanis, 2010; Wong, Wong, \& Leung, 2010).

Based on the estimation of the default risk, in this case we can do a separation between banks seen as riskier and toward those seen as less risky. Researchers have tried then to ameliorate models able to predict the potential financial distress in different sectors and in different countries. They actually used several statistical methods to accomplish this objective. Among these methods we can notice:

Discriminant analysis (Sinkey, 1975; Altman, 1968; Lin, 2009; Giovanis, 2010; Kouki \& Elkhaldi, 2011), logistic regression (Thomson, 1991; Gonzalez-Hermosillo, 1999; Godlewski, 2004; Montgomery, Hanh, Santoso, \& Besar, 2005; Lin, 2009; Giovanis, 2010; Messai \& Jouini, 2013a). We could also notice that the Probit regression is a multivariate statistical method that was used to predict bankruptcies for some ailing banks (Barr \& Siems, 1994; Doganay, Ceylan, \& Aktas, 2006; Lin, 2009; Wong et al., 2010). 


\subsection{Traditional Methods}

Several researchers have tried also to expand their studies by using multiple methods, to choose the most appropriate and to show that one of them is most effective. Among the authors who used several prediction methods, we could mention Donganay et al. (2006) and Wong et al. (2010) studies.

Doganay et al. (2006) have developed an early warning system for predicting at least three years before the banking failure using three methods: Logit, Probit and discriminant analyses. These authors incorporated multivariate statistical regressions and used 27 ratios to predict the failure. The sample included distressed banks during the period 1997-2002. This sample is composed of 42 banks and 19 of them failed. The authors found that the most appropriate model for predicting bank distress is logit.

Similarly, Konstandina (2006) used logit analysis to predict the failure of Russian banks. She used 6 macroeconomic factors and 13 factors specific to banks as independent variables. She also used another proportional hazard model that identifies the factors influencing the time resistance of a bank during a financial crisis. She found that the increase in bad debts and also that holding treasury bills enhance the risk of the bank distress. On the other hand, Andersen (2008) used the logit method in order to identify the most relevant variables in detecting distress in Norwegian banks. He distinguished 23 of explanatory variables of bank distress. He determined six relevant variables inherent to the CAEL rating system presented as follows: capital adequacy, asset quality, earnings ability and liquidity. Mayes and Stremmel (2012) used also logit method and survival time analysis in order to predict banking failure. The models incorporate CAMELS indicators. These authors explain that the risk weighted capital adequacy and the adjusted leverage ratio are the most relevant indicators of a bank distress.

\subsection{The Methods of Artificial Intelligence}

The artificial neural networks have made their entry in management science as a quantitative prediction method since 1990 (Paquet, 1997).

This method has been improved after the emergence of new and sophisticated techniques. These models have been recently applied to finance and they are called Adaptive Neuro-Fuzzy inference system (ANFIS). Moreover, ANFIS model is considered very effective in predicting an event or a failure (Kiran \& Rajput, 2011).

Boyacioglu, Kara, \& Baykan (2009) consider that bank failure threaten the resilience of a system as a whole. Therefore, they categorize banks as distressed and non distressed ones. They try to test classification performances for various neural network techniques. They used 20 financial ratios based on CAMELS acronym. Four techniques are employed: multi-layer perceptron, learning vector quantization, competitive learning and self organizing map. The findings of this research show that learning vector quantization and the multi-layer perceptron are the most effective models for predicting failure. Fioramanti, (2009) highlights the flexibility of neural networks and their ability to approximate nonlinear relationships. The operation of the ANN method is similar to the human brain logic by using highly non-linear approximation functions.

Yildiz and Akkoc (2010) have developed neural networks based on a Neuro Fuzzy technique. The authors define it as a method that combines two approaches, namely neural networks and fuzzy logic. It looks like a hybrid artificial intelligence technique. This new method was also adopted to predict bankruptcies in the Turkish banking sector. In fact, they chose a sample of 55 Turkish banks: 19 fundamentally robust banks and 36 failed banks. The success of prediction was made after the use of Neuro Fuzzy model is $90.91 \%$. The application of neural networks and multivariate discriminant analysis was done primarily to compare it with the Neuro-Fuzzy model. The performance of the first two methods is respectively $86.36 \%$ and $81.82 \%$. Although there is no big difference between the performances of models, the authors concluded that this new Neuro-Fuzzy method was slightly more successful. Giovanis (2010) presents a suiTable model of early warning distress using logistic regression and ANFIS model panel (Adaptive Neuro-Fuzzy Inference System). To check if a company is distressed, Giovanis (2010) follows the logic applied by Gentry et al. (1985).

A firm that reduces the dividend is in a financial distress. With random effects logit model, the author has performed better forecasts than those found using a simple binary logistic regression. Using Neuro-fuzzy system (ANFIS), the author concluded that it is a more appropriate tool for financial risk managers and decision making in Central Banks. The sample is composed of 179 financial institutions in Taiwan Security Exchange (TSE) during 2002-2008. The author finally concluded that the neural model is useful in predicting bankruptcies (global and also national economic crises). He also noted that this model outperforms significantly the logit regression, indicating that it is actually the most appropriate tool for financial risk managers and economic policy makers in central banks and national statistical offices. 
The author concluded also that the use of this technique is much better than previous methods. Furthermore, using data related to developing countries during periods of sovereign debt crises can lead to a progress by applying a less developed non-parametric method based on artificial neural networks (ANN) (Fioramanti, 2009; Boyacioglu, Kara, \& Baykan, 2009).

Similarly, Sevim, Oztekim, Bali, Gumus, \& Gursen (2014) develop an early warning system to predict currency crisis. These authors used three methods: logit regression, decision tree and artificial neural networks. The main finding consists that the Turkish economy is not expected to face a currency crisis. It resists until the end of 2012.

\section{Sample, Variables and Methodology}

The sample for this study encompasses 618 banks in 18 countries in Europe during 2007 to 2011. Financial data were retrieved from Bankscope database. Our work is based on financial variables representing financial soundness indicators.

Table 1. Presentation of sample

\begin{tabular}{|c|c|c|c|c|c|c|c|}
\hline \multirow{2}{*}{ Countries } & \multirow{2}{*}{ Code } & & nks & \multirow{2}{*}{ Countries } & \multirow{2}{*}{ Code } & \multirow{2}{*}{\multicolumn{2}{|c|}{$\begin{array}{c}\text { Banks } \\
\text { Number Percent }\end{array}$}} \\
\hline & & \multicolumn{2}{|c|}{ Number Percent } & & & & \\
\hline Austria & AT & 10 & $1.62 \%$ & United kingdom & GB & 60 & $9.71 \%$ \\
\hline Belgium & $\mathrm{BE}$ & 9 & $1.46 \%$ & Greece & GR & 13 & $2.1 \%$ \\
\hline Switzerland & $\mathrm{CH}$ & 94 & $15.21 \%$ & Ireland & IE & 9 & $1.46 \%$ \\
\hline Germany & $\mathrm{DE}$ & 12 & $1.94 \%$ & Italy & IT & 89 & $14.4 \%$ \\
\hline Denmark & DK & 22 & $3.56 \%$ & Netherland & $\mathrm{NL}$ & 14 & $2.26 \%$ \\
\hline Spain & ES & 33 & $5.34 \%$ & Norway & NO & 75 & $12.14 \%$ \\
\hline Finland & FI & 5 & $0,81 \%$ & Portugal & PT & 19 & $3.1 \%$ \\
\hline France & FR & 96 & $15.53 \%$ & Sweden & SE & 58 & $9.38 \%$ \\
\hline
\end{tabular}

The distress of a bank is determined based on the non performing loans to gross Loans ratio (NPLGL). Several studies opted for this choice as Reinhart and Rogoff (2010) who consider non performing loans as a proxy for financial crises and state that the presence of these non performing loans is a signal of potential financial crisis. Similarly, Messai and Jouini (2013b) and Vogiazas and Nikolaidou (2011) confirm that the high percentage of non performing loans, both in developed and in emerging countries is often associated with bank distress and financial crises.

In addition to this variable, the empirical literature review demonstrates the existence of other proxies of distress such as provisions for loan losses and solvency ratio (equity to total assets). Sorge and Virolainen (2006) focus on credit risk and liquidity risk. The authors present a model for the relationship between the provisions for loan losses and relevant macroeconomic factors.

Banks with low non performing loans ratio compared to those with higher one would be classified as highly distressed. In fact, according to Lin (2010), the sample should be decomposed in quartile.

Also, a bank is considered in a serious trouble when the non performing loans ratio is greater than the third quartile $(\mathrm{Q} 3=4.851 \%)$ for two successive years. Otherwise, the bank hasn't been distressed.

Our dependent variable will be presented by a binary variable: It is equal to 1 bank is in distress i.e. when non performing loans ratio is greater than $4.851 \%$ for two successive years. It is equal to 0 otherwise.

To explain the financial distress of banks, we choose 10 ratios that belong to the acronym CAMEL.

Table 2. Overview and definition of variables

\begin{tabular}{cccc}
\hline Variables & Definition & CAMEL & Expected sign \\
\hline EQTA & Equity / total assets & Capital Adequacy & - \\
EQNL & Equity /net loans & Capital Adequacy & - \\
LLPGL & LLP/gross loans & Asset quality & + \\
LLRNPL & LLR/NPL & Asset quality & - \\
CIR & Cost to income ratio & Management quality & + \\
ROEA & Return on equity average & Equity & $+/-$ \\
ROAA & Return on assets average & Equity & $+/-$ \\
LIQTA & Liquidity /total assets & Liquidity & - \\
LIQDEP & Liquidity /Customer \& S. T. Funding & Liquidity & - \\
NLDEP & net loans/ deposit & Liquidity & $+/-$ \\
\hline
\end{tabular}


Predicting difficulties faced by a bank can be carried out before one or two years, if a bank has a ratio higher than the third quartile (Q3) for two successive years (2009 and 2010), it is considered in distress for 2011.Our paper is based on three methods: discriminant analysis, logit, and neural network (ANN).

\section{Analysis and Results Interpretation}

Using the Pearson correlation matrix, we measured the correlation between the independent variables. We can then observe a strong correlation between certain variables such as equity to total assets ratio (EQTA) and equity to net loans ratio (EQNL). We reached the same conclusion for Return on equity average (ROEA) and Return on assets average (ROAA) and also for liquidity to total assets (LIQTA), liquidity to deposits (LIQDEP).

In fact, among 10 ratios, we only used 7 ratios whose correlation coefficient was less than 0.5 . These variables will be the object of our analysis using these methods: discriminant analysis, logistic analysis and the artificial neural network.

In fuzzy logic we will consider only significant variables and the results obtained by other methods mentioned above. We follow also Giovanis's approach (2010).

\subsection{Discriminant Analysis}

The Discriminant analysis model was presented to predict business failure. In this model different information from multiple variables was combined with a single weighted score for each one (Ray, 2011). This score was calculated using the following general discriminant function:

$$
Z_{i}=\alpha_{0}+\alpha_{1} x_{1}+\alpha_{2} x_{2}+\cdots+\alpha_{n} x_{n}
$$

Where $\mathrm{Z}$ is the score, $\mathrm{xi}$ is the independent variables, and $\alpha \mathrm{i}, \alpha_{0}$ are the estimated coefficients.

The application of the discriminant analysis model using the method "step by step", allow us to select three ratios respectively loan loss provisions to gross loans (LLPGL), loan loss reserves to nonperforming loans ratio (LLRNPL) and equity to net loans ratio(EQNL).

The equation is designed as follows:

$$
Z_{i}=-0.021+0.62 L L P G L-0.673 L L R N P L \text { (one year) }
$$

The percentage classification model for discriminant analysis is equal to $77.7 \%$. The Table below (Table2) shows the obtained results by the discriminant analysis model.

Table 3. Prevision results one year before the distress

\begin{tabular}{cccccc}
\hline & & \multicolumn{2}{c}{ Expected classification } & Total \\
\cline { 3 - 5 } & & Distress & 0 & 1 & 433 \\
& \multirow{4}{*}{ Original } & 0 & 375 & 58 & 185 \\
& \multirow{2}{*}{ Effective } & 1 & 80 & 105 & 100.0 \\
& \multirow{2}{*}{$\%$} & 0 & 86.6 & 13.4 & 100.0 \\
\hline
\end{tabular}

The percentage of correct classification is equal to $77.7 \%$

The application of the method of discriminant analysis for two years provides the following Table:

$$
Z_{i}=-0.019+0.467 L L P G L-0.649 L L R N P L
$$

The percentage in the discriminant analysis gives an overall ranking of $77.3 \%$. The Table below (Table3) shows the results expected by the discriminant analysis model.

Table 4. Result of a Ranking two years before the distress

\begin{tabular}{cccccc}
\hline & & \multicolumn{2}{c}{ Expected classification } & \\
\cline { 3 - 4 } & & Distress & 0 & 1 & Total \\
\hline \multirow{4}{*}{ Original } & \multirow{3}{*}{ Effective } & 0 & 384 & 49 & 433 \\
& & 1 & 91 & 94 & 185 \\
& $\%$ & 0 & 88.7 & 11.3 & 100.0 \\
\hline
\end{tabular}

The percentage of correct classification was equal to $77.3 \%$ 
In this Table, we can notice that the model is able to correctly classify 375 robust banks of a total of 433 . The precision model was equal to $86.6 \%$. This model can also classify correctly 105 distressed banks of a total of 185. Then, it can provide $56.8 \%$ precision for the group of distressed banks. Then the global percentage of a good ranking is equal to $77.7 \%$. In the second case, we seek to predict distress before two years. This model was able to classify correctly, 384 of a total of 433 robust banks. The good ranking of healthy banks reaches $88.7 \%$. In the case of the distressed banks, this model reached to classify correctly, 94 for a total of 185 distressed banks. The good ranking reached $50.81 \%$. Then the global percentage of a good classification is equal to $77.3 \%$.

\subsection{Logit Method}

The logistic regression method is characterized by a binary dependent variable.

For the bank (i) we have:

$$
\begin{gathered}
Y_{i}=\left\{\begin{array}{l}
0, \alpha_{0}+\sum_{i=1}^{n} \beta_{i} x_{i}+\varepsilon_{i} \leq 0 \\
1, \alpha_{0}+\sum_{i=1}^{n} \beta_{i} x_{i}+\varepsilon_{i}>0
\end{array}\right. \\
p_{i}=P\left(Y_{i}=1\right)=P\left(\alpha_{0}+\sum_{i=1}^{n} \beta_{i} x_{i}+\varepsilon_{i}>0\right)=\frac{1}{1+e^{-\alpha_{i}-\sum \beta_{i} x_{i}}} \\
\log \frac{p_{i}}{1-p_{i}}=\alpha_{i}+\sum \beta_{i} x_{i}
\end{gathered}
$$

With $\frac{p_{i}}{1-p_{i}}$ is the relative probability of $Y_{i}=1$

The use of logistic method one year before the distress shows that loan loss provision to gross loans (LLPGL) and loan loss reserves to non performing loans (LLRNPL) ratios are significant at a level of $1 \%$ while the ROEA ratio is significant at a level of $10 \%$.

Table 5. Estimation result using logistic regression during a year of distress

\begin{tabular}{ccc}
\hline Variables & Coefficients & t student \\
\hline EQNL & 2.092025 & $2.16^{* *}$ \\
LLPGL & 0.9897102 & $6.18^{* * *}$ \\
LLRNPL & -1.398115 & $-4.70^{* * *}$ \\
CIR & -0.7391725 & -1.17 \\
ROEA & -0.2284727 & -0.22 \\
LIQTA & -0.1538859 & -0.19 \\
NLDEP & -0.0208422 & -0.15 \\
Cte & -0.485183 & -0.90 \\
LR chi2(7) & 105.61 & \\
$\mathbf{R}^{2}$ & 0.14 & \\
\hline
\end{tabular}

The percentage of correct classification was equal to $76.05 \%$.

The use of the logit method two years before financial distress indicates that three ratios are significant. Those ratios are EQNL, LLPGL and LLRNPL. Equity to Net Loans ratio is considered as a buffer to absorb potential losses that can be faced by banks. A high percentage of capital implies lower risk of distress and helps to absorb potential losses (Mayes \& Stremmel, 2012). This ratio is significant at a level of 5\%. The other ratios are significant at a level of $1 \%$. Our results improve the idea that a better profitability encourages banks to take excessive risks and increases the likelihood of distress. Equity to Net Loans ratio (EQNL) measures the efficiency with which institutions use their own funds. It can also provide information about the viability of their own funds. A high ratio could indicate high profitability and / or low capitalization. Loan loss reserves to Non performing loans (LLRNPL) is considered as a coverage ratio of non performing loans. As a consequence, there is a negative relationship between this ratio and bank distress. 
Table 6. Estimation result using logistic regression for two years of distress

\begin{tabular}{ccc}
\hline Variables & Coefficients & t student \\
\hline EQNL & 0.8917947 & 0.86 \\
LLPGL & 0.8427689 & $6.62^{* * *}$ \\
LLRNPL & -1.465278 & $-4.21^{* * *}$ \\
CIR & 0.1465523 & 0.38 \\
ROEA & -0.1563443 & -0.20 \\
LIQTA & -0.2673611 & -0.32 \\
NLDEP & 0.1411453 & 0.97 \\
Cte & -1.105471 & $-2.59^{* * *}$ \\
LR chi2(7) & 114.33 & \\
$\mathbf{R}^{\mathbf{2}}$ & 0.1516 & \\
\hline
\end{tabular}

Note. $\left({ }^{* * *}\right)$ significant at level $1 \%$.

The percentage of correct classification was equal $77.02 \%$.

The predicting process using the logit regression shows that only two ratios were significant at a level of $1 \%$ namely: loan losses provisions to gross loans (LLPGL) and loan losses reserves to non performing loans ratio (LLRNPL). That improves the idea that prevision can be more efficient one year before the distress.

Confusion matrix in Table 7 indicates that percentages of classifications one year before the distress are as follows: in fact, that matrix indicates good ranking of distressed banks equal to $31.81 \%$ and a good ranking of solid banks equal to $95,38 \%$. Two years before the distress, this matrix indicates a good ranking of healthy banks which is equal to $97.4 \%$ then a good ranking of distressed banks equal to $29.19 \%$.

Table 7. The Confusion matrix

\begin{tabular}{|c|c|c|c|c|c|c|}
\hline \multicolumn{4}{|c|}{ Before one year } & \multicolumn{3}{|c|}{ Before two years } \\
\hline & \multicolumn{2}{|c|}{ True } & & \multicolumn{2}{|c|}{ True } & \\
\hline Classified & 1 & 0 & Total & 1 & 0 & Total \\
\hline 1 & 57 & 20 & 77 & 54 & 11 & 65 \\
\hline $\mathbf{0}$ & 128 & 413 & 541 & 131 & 422 & 553 \\
\hline Total & 185 & 433 & 618 & 185 & 433 & 618 \\
\hline
\end{tabular}

This matrix indicates the percentages of classification one and two years before the distress. In fact, the better ranking of solid banks was equal to $95.38 \%$ and the good ranking for distressed banks was equal to $30.81 \%$. In The case of two years, confusion matrix indicates that good ranking of solid and distressed banks was respectively equal to 97.46 and $29.19 \%$.

\subsection{Artificial Intelligence Method}

The application of neural techniques to the same data allows us to take into account the non-linearity of variables. We refer to Boyacioglu, et al. (2009) research' and we used the Multi-Layer Perceptron (MLP) and we should also note that this network includes one or more hidden layers neurons. The connections between these layers are direct and total.

Our overall sample is divided into three sub-samples: the construction sample (70\%), the test sample (15\%) and the validation sample (15\%).

The neural network has the following features:

- An input layer consists of 7 neurons corresponding to independent variables xi.

- A hidden layer consists of $\mathrm{N}$ neurons, only after several tests on the sample, the number which represents an optimum value of learning and generalization will be achieved. 


\section{NEURONS}

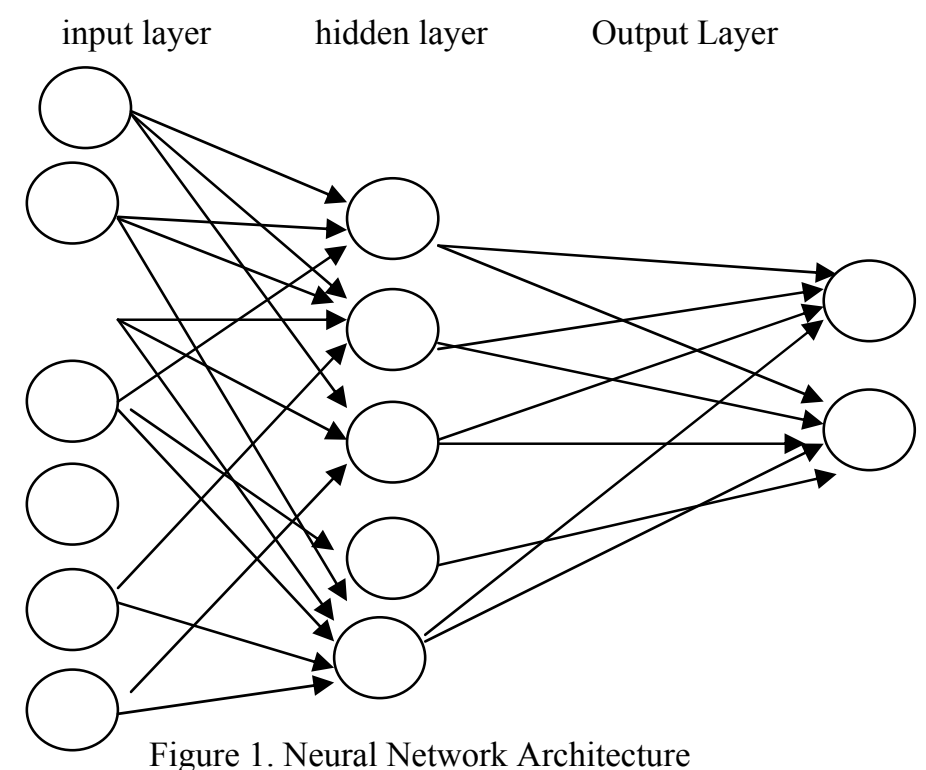

Two activation functions were used as below:

-The sigmoid function for the output layer

$$
f(x)=\frac{1}{e^{x}+e^{-x}}
$$

- The hyperbolic tangent function for the hidden layer

$$
g(x)=\frac{e^{x}-e^{-x}}{e^{x}+e^{-x}}
$$

The neurons of the hidden layer are determined based on the transfer function or activation of $\mathrm{g}(\mathrm{x})$ :

$$
y_{i}=g(x)=\sum_{i=1}^{n} w_{i j} x_{i}+w_{o j}
$$

The activation function $\mathrm{f}(\mathrm{k}, \mathrm{x})$ determines the output layers:

$$
O_{k}=f(k, x)=\sum_{j=1}^{p} w_{j k} \cdot g\left(\sum_{i=1}^{n} w_{i j} x_{i}+w_{o j}\right)+w_{0 k}
$$

With $\mathrm{i}$ : the number of input variables $\mathrm{i}=1 \ldots . . \mathrm{n}$

$x_{\mathrm{i}}$ : neurons of the hidden layer

$y_{\mathrm{j}}$ : neurons of the hidden layer

$j:$ number of hidden layer $\mathrm{j}=1 \ldots \ldots . . \mathrm{p}$

$\mathrm{O}_{\mathrm{k}}$ : The neurons of the output layer

The learning of such a network is monitored and the algorithm uses the back propagation of the error. This algorithm is used in the feed forward type networks. Each network of neurons has an input layer, an output layer, and at least one hidden layer.

The retro-propagation is based on presenting to the network an input vector, then, it calculates the output. It starts from the input layer, and it goes through the other layers until the output layer. This output is compared to the desired output, an error is then obtained. This error, is calculated from the output layer towards the input layer (retro propagation). This allows modification of the network weights and the learning process. It is essential to perform a normalization of all input data. Otherwise the quality of results is negatively affected. In other words, if the inputs have very different sizes, small ones will have no influence on the learning process (Boyacioglu, Kara, \& Baykan, 2009).

Rescaling is the most commonly used normalization method. It is based on subtracting the minimum and dividing the result by the interval (x-min) / (max-min). The normalized values are between 0 and 1 . 
The number of neurons is selected by the lowest RMSE (Root Mean Square Error) coefficient.

$$
R M S E=\sqrt{\frac{\sum_{i=1}^{n}\left(y_{i}-\hat{y}_{i}\right)^{2}}{n}}
$$

The RMSE application offered a "check out" system by which the number of neurons could be verified. As a criterion for determining the number of neurons, RMSE allowed us to have five hidden layers neurons (see Table $8)$.

Table 8. Determination of the number of neurons in the hidden layer

\begin{tabular}{|c|c|c|c|c|c|c|}
\hline \multirow{3}{*}{ Layer } & \multicolumn{3}{|c|}{2010} & \multicolumn{3}{|c|}{2009} \\
\hline & \multirow{2}{*}{ Iteration } & \multicolumn{2}{|c|}{ RMSE } & \multirow{2}{*}{ Iteration } & \multicolumn{2}{|c|}{ RMSE } \\
\hline & & Training & Testing & & training & testing \\
\hline 1 & 12 & 0.44537625 & 0.38310573 & 22 & 0.458692708 & 0.444330958 \\
\hline 2 & 29 & 0.43528382 & 0.45536798 & 11 & 0.434833301 & 0.459964129 \\
\hline 3 & 27 & 0.4168345 & 0.41148147 & 18 & 0.44964208 & 0.465382638 \\
\hline 4 & 51 & 0.40807107 & 0.40895232 & 18 & 0.425323406 & 0.447752164 \\
\hline$\underline{\mathbf{5}}$ & $\underline{65}$ & $\underline{0.39410785}$ & $\underline{0.38097769}$ & $\underline{56}$ & $\underline{0.4035889}$ & $\underline{0.401105971}$ \\
\hline$\overline{6}$ & $\overline{23}$ & $\overline{0.42228071}$ & $\overline{0.39107928}$ & $\overline{3}$ & $0 . \overline{542200148}$ & $\overline{0.528742849}$ \\
\hline 7 & 21 & 0.40161922 & 0.43032081 & 9 & 0.451464284 & 0.462893076 \\
\hline 8 & 48 & 0.39817458 & 0.39244235 & 17 & 0.450967848 & 0.471924782 \\
\hline 9 & 19 & 0.4315449 & 0.42194549 & 28 & 0.416659333 & 0.4181758 \\
\hline 10 & 19 & 0.44705257 & 0.4253716 & 30 & 0.453688219 & 0.458991285 \\
\hline 11 & 24 & 0.39761288 & 0.39829637 & 14 & 0.441430629 & 0.476223687 \\
\hline 12 & 13 & 0.4756238 & 0.4494619 & 10 & 0.469316524 & 0.449780391 \\
\hline 13 & 28 & 0.39597348 & 0.39647194 & 3 & 0.537913562 & 0.497297698 \\
\hline 14 & 12 & 0.40634468 & 0.43537915 & 23 & 0.416661733 & 0.414518998 \\
\hline 15 & 12 & 0.45415856 & 0.42618541 & 30 & 0.456678224 & 0.434164715 \\
\hline
\end{tabular}

The application of ANN method demonstrates that the most important variables in predicting distress (one year before the distress) are loan loss provisions to gross loans ratio (LLPGL), loan loss reserves to non performing loans (LLRNPL) and return on equity average (ROEA), respectively, with importance rate $100 \%, 57 \%$ and $27 \%$. Regarding two years before the distress, the most important ratios for predicting bank distress are loan loss provisions to gross loans ratio (LLPGL), loan loss reserves to non performing loans (LLRNPL) and cost to income ratio (CIR), respectively, with importance rate $100 \%, 61.4 \%$ and $45.1 \%$.

The Table 9 reveals the percentage of the most appropriate ratio to prevent bank distress. The result demonstrates the significant role given to loan loss provisions to gross loans ratio (LLPGL). This variable would be able to predict distress at the right moment. Indeed, banks must make provisions for loan losses in case of emergence of non-performing loans (Messai \& Jouini, 2013b).

Table 9. Importance of independent variables

\begin{tabular}{ccccc}
\hline & \multicolumn{2}{c}{ Before one year } & \multicolumn{2}{c}{ Before two years } \\
\hline & Importance & Percent & Importance & Percent \\
\cline { 2 - 5 } EQ/TL & 0.060 & $14.5 \%$ & 0.067 & $21.4 \%$ \\
LLP/GL & 0.413 & $100.0 \%$ & 0.312 & $100.0 \%$ \\
LLR/NPL & 0.235 & $57.0 \%$ & 0.192 & $61.4 \%$ \\
CIR & 0.068 & $16.5 \%$ & 0.141 & $45.1 \%$ \\
ROEA & 0.111 & $27.0 \%$ & 0.102 & $32.6 \%$ \\
LIQ/TA & 0.039 & $9.4 \%$ & 0.081 & $25.9 \%$ \\
NL/DEP & 0.074 & $18.0 \%$ & 0.106 & $34.0 \%$ \\
\hline
\end{tabular}

Table 10 shows that the method of neural network is the best to predict distress. This method has a global performance equal to $80.6 \%$ and $79.8 \%$, respectively one year and two years before the distress. 
The prediction has been made a couple of times: one and two years before the distress. The prediction before one year indicates that prevision performance in the discriminant analysis, logic method and neural networks are respectively $77.7 \%, 76.02 \%$, and $80.6 \%$. Then, the prevision before two years indicates that the prevision's performance in the discriminant analysis, logistic method and neural networks are respectively $77.3 \%, 77.02 \%$ and $79.6 \%$. This improves another time that the neural network method outperforms the two others (logit and discriminant analysis). These results confirm those obtained by Giovanis, (2010) and would be contrary to the result reached by Doganay, (2006) according to which logit is the best model to predict bank distress.

This study allowed us to conclude that the positive predictive value have correctly presaged a classification percentage of distressed banks. This percentage is greater than $50 \%$ for two models, namely discriminant analysis and neural networks.

Table 10. Classification one and two years before the distress

\begin{tabular}{|c|c|c|c|c|c|c|c|}
\hline & \multirow{3}{*}{ Sample } & \multicolumn{6}{|c|}{ Previsions } \\
\hline & & \multicolumn{3}{|c|}{ Before one year } & \multicolumn{3}{|c|}{ Before two years } \\
\hline & & 0 & 1 & Correct percentage & 0 & 1 & Correct percentage \\
\hline \multirow{4}{*}{ Training } & 0 & 277 & 21 & $93.0 \%$ & 276 & 23 & $92.3 \%$ \\
\hline & 1 & 64 & 65 & $50.4 \%$ & 62 & 64 & $50.8 \%$ \\
\hline & Global percentage & $79.9 \%$ & $20.1 \%$ & $80.1 \%$ & $79.5 \%$ & $20.5 \%$ & $80.0 \%$ \\
\hline & 0 & 124 & 11 & $91.9 \%$ & 126 & 8 & $94.0 \%$ \\
\hline \multirow{2}{*}{ Testing } & 1 & 26 & 30 & $53.6 \%$ & 31 & 28 & $47.5 \%$ \\
\hline & Global percentage & $78.5 \%$ & $21.5 \%$ & $80.6 \%$ & $81.3 \%$ & $18.7 \%$ & $79.8 \%$ \\
\hline
\end{tabular}

An error type I corresponds to a classification of a failed bank as robust and an error Type II is a classification of a healthy bank as distressed. Concerning error percentages, we notice that the lowest error is obtained after using the neural network model. As for the most important error, it was observed after using the logit model (23.96\%). The error type II was largely observed after the use of the discriminant analysis method (35.58\%). For the purpose, this confirms the results we have achieved (see Table 11).

Table 11. Summary table

\begin{tabular}{ccccccccc}
\hline Method & \multicolumn{2}{c}{ Discriminant analysis } & \multicolumn{2}{c}{ Logit } & \multicolumn{2}{c}{ Neural networks (training) } & Neural networks (testing) \\
\hline 1 or 2 years before distress & 1 & 2 & 1 & 2 & 1 & 2 & 1 & 2 \\
Positive predictive value (\%) & 56.75 & 50.81 & 30.81 & 29.19 & 53.57 & 47.46 & 50.39 & 50.79 \\
Negative predictive value (\%) & 86.6 & 88.68 & 95.38 & 97.46 & 91.85 & 94.03 & 92.95 & 92.31 \\
Error type I (\%) & 17.58 & 19.16 & 23.66 & 23.69 & 17.33 & 19.74 & 18.76 & 18.34 \\
Error type II (\%) & 35.58 & 34.27 & 25.97 & 16.923 & 28.21 & 21.05 & 24.42 & 26.44 \\
Global performance (\%) & 77.7 & 77.3 & 76.05 & 77.02 & 80.1 & 80 & 80.6 & 79.8 \\
\hline
\end{tabular}

Note. Errors type I and type II: provide false alarm.

Finally, we consider that neural network is the best method to predict distress. On the one hand it has the best percentage of prediction. On the other hand it appears that the percentage of the error type I (false positive) is equal to $17.33 \%$ and is the lowest compared with percentage provided by the two other methods.

\section{Conclusion}

During the two last decades, several authors have focused on methods of forecasting the bank distress. The aim of this study is to determine the most relevant indicators of financial distress in European countries in order to avoid potential crises. The prevision was carried out one and two years before that distress would occur. In this study, we have opted for the ratio non performing loans to gross loans as predictor of bank distress. We have also opted for three methods in order to choose the most appropriate one. This comparison aims to highlight the usefulness of these different methods and to decide about the effectiveness of each method in a microprudential framework. We observe that influence of internal factors on the non performing loans to gross loans ratio (NPLGL) was very significant. Therefore, we concluded that distress could be explained by a high percentage of non-performing loans by banks in expansion periods, because during these periods banks undertake more risks such as excessive lending activities without considering the quality of each loan. We recall the example, in the 
Japanese crisis in the 1980s, when banks continued heavily the granting of loans without checking if there are legal certainties over ownership building lands. The same thing happened during the subprime crisis. So, in this study, we want to determine the best distress indicators. Our results suggest also that CAMEL indicators remain the only rating system to put the most relevant and important ratios to predict distress. The dependent variable, then, can be expressed by internal factors inherent to banks, which are presented by CAMEL criteria. The best percentage of prediction is obtained when we use the method of neural networks. The performance achieved by this model before one and two years was respectively equal to $80.6 \%$ and $79.8 \%$. As a consequence, using internal financial soundness indicators is too important to predict distress in individual banks. However, our study has a number of limitations. The distress prediction need to be used in both macro and micro prudential approaches. These two approaches are very complementary and related. Future research on distress prediction may be extended as follows: First, variables relating to a macroeconomic environment should be encompassed in order to define relevant factors which could explain distress in a macroeconomic approach (stress testing framework). Second, extending the methods of prediction and add survive analysis in order to predict difficulties. Finally, using several financial variables as well as macroeconomic variables in order to choose the most relevant leading indicators of distress and in order to enhance the robustness of the results in a stress testing framework (Anderson, 2008; Lelyveld, 2009; Quagliariello, 2009).

\section{References}

Akhter, S., \& Daly, K. (2010). Macroeconomic determinants of credit risk: Recent evidence from a cross country study. International Review of Financial Analysis, 19(3), 165-171. http://dx.doi.org/10.1016/j.irfa.2010. 03.001

Altman, E. I. (1968). Financial Ratios, Discriminant Analysis and the Prediction of Corporate Bankruptcy. The Journal of Finance, 23, 589-609. Retrieved from http://BARRdx.doi.org/10.2307/2978933

Andersen, H. (2008). Stress testing of bank's profit and capital adequacy. Norges Bank Economic Bulletin, 79, 47-57. Retrieved from http://www.norges-bank.no/Upload/71739/EN/Stress_testing.pdf

Barr, R. S., \& Siems, T. F. (1996). Bank Failure Prediction using DEA to Measure Management Quality. Interfaces in Computer Science and Operations Research, 341-365, http://dx.doi.org/10.1007/978-1-46154102-8_ 15

Boyacioglu, M. A., Kara, Y., \& Baykan, O. K. (2009). Predicting bank financial failures using neural networks, support vector machines and multivariate statistical methods: A comparative analysis in the sample of savings deposit insurance fund (SDIF) transferred banks in Turkey. Expert Systems with Applications, 36, 3355- 3366. http://dx.doi.org/10.1016/j.eswa.2008.01.003

Cardarelli, R., Elekdag, S., \& Lall, S. (2011). Financial stress and economic contractions. Journal of financial Stability, 7(2), 78-97. http://dx.doi.org/10.1016/j.jfs.2010.01.005

Cihak, M. (2007). Introduction to applied stress testing. International Monetary Fund. Working paper No. 07/59, pp. 1-74. http://dx.doi.org/10.5089/9781451866230.001

Demyanyk, Y., \& Hasan, I. (2010). Financial crises and bank failures: A review of prediction methods. Omega, 38(5), 315-324. http://dx.doi.org/10.2139/ssrn.1518368

Doganay, M., Ceylan, N., \& Aktas, R. (2006). Predicting Financial Failure of the Turkish Banks. Annals of Financial Economics, 2(1), 97-117. http://dx.doi.org/10.1142/S2010495206500059

Fioramanti, M. (2009). Predicting sovereign debt crises using artificial neural networks: A comparative approach. Journal of Financial Stability, 4, 149-164. http://dx.doi.org/10.2139/ssrn.1518368

Gentry, J. A., Newbold, P., \& Whitford, W. (1985). Classifying bankrupt firms with funds flow components. Journal of Accounting Research, 46-160. http://dx.doi.org/10.2307/2490911

Giovanis, E. (2010). A Study of Panel Logit Model and Adaptive Neuro-Fuzzy Inference System in the Prediction of Financial Distress Periods. World Academy of Science, Engineering and Technology, 4(4), 540-546. http://waset.org/publications/7348

Godlewski, C. J. (2004). Le Rôle de l'Environnement Réglementaire, Légal et Institutionnel dans la Défaillance des Banques Le Cas des Pays Emergents. Banque et marchés, 73, 20-31. Retrieved from http://www.revue-banque.fr/article/role-environnement-reglementaire-legal-institution

Gonzalez-Hermosillo, B. (1999). Determinants of Ex-Ante Banking System Distress: A Macro-Micro Empirical Exploration of Some Recent Episodes. International Monetary Fund. Working Paper No. 33. Retrieved 
from http://www.imf.org/external/pubs/ft/wp/1999/wp9933.pdf

Kiran, T. R., \& Rajput, S. (2011). An effectiveness model for an indirect evaporative cooling (IEC) system: Comparison of artificial neural networks (ANN), adaptive neuro-fuzzy inference system (ANFIS) and fuzzy inference system (FIS) approach. Applied Soft Computing, 11(4), 3525-3533. http://dx.doi.org/10.1016/j. asoc.2011.01.025

Konstandina, N. (2006). Probability of Bank Failure: The Russian Case. Economic Education and Research Consortium. Working Paper, No. 06/01. Retrieved from http://eercnetwork.com/default/download/creater/ working_papers/file/c251e775ae93dd556f0a09cad148701af7c25f37.pdf

Kouki, M., \& Elkhaldi, A. (2011). Toward a Predicting Model of Firm Bankruptcy: Evidence from the Tunisian Context. Middle Eastern Finance and Economics, 14, 26-43. Retrieved from http://www.middleeastern economicsandfinance.com/issues/MEFE_14.html

Kulthunga, A., \& Rehman, S. (2012). Banking Sector Soundness, Innovation, and Development: Emerging Europe and South Asia. Archive of European Integration, ACES Working Papers, 1-26. Retrieved from http://aei.pitt.edu/59197/1/ACESWP_Chp_3_Kulathunga_2012.pdf

Lelyveld, I. (2009).Stress testing: The link between Macro and Micro. The international Journal of Central Banking, 5(3). Retrieved from http://www.ijcb.org/journal/ijcb09q3intro.pdf

Lin, S. L. (2010). A two-stage logistic regression-ANN model for the prediction of distress banks: Evidence from 11 emerging countries. African Journal of Business Management, 14(4), 3149-3168. Retrieved from http://www.academicjournals.org/article/article1380731107_Lin.pdf

Lin, T. (2009). A cross model study of corporate financial distress prediction in Taiwan: Multiple discriminant analysis, logit,probit and neural networks models. Neurocomputing, 72, 3507-3516. http://dx.doi.org/10. 1016/j.neucom.2009.02.018

Mager, F., \& Shmeider, C. (2009). Stress-testing German credit portfolios. Journal of Risk Model Validation. 3(3), 27-45. Retrieved from http://m.risk.net/digital_assets/5005/jrm_v3n3a2.pdf

Mayes, D. G., \& Stremmel, H. (2012). The Effectiveness of Capital Adequacy Measures in Predicting Bank Distress. The European Money and Finance Forum, 1, 1-53. Retrieved from http://www.suerf.org/down load/studies/study20141.pdf

Messai, A. S., \& Jouini, F. (2013a). Predicting banking distress in European countries. Journal of economic and social studies, 3(1), 61-82. http://dx.doi.org/10.14706/JECOSS11312

Messai, A. S., \& Jouini, F. (2013b). Micro and macro determinants of non performing loans. International Journal of Economics and Financial Issues, 3(4), 852-860. Retrieved from http://www.econjournals.com/ index.php/ijefi/article/viewFile/517/pdf

Montgomery, H., Hanh, T. B., Santoso, W., \& Besar, D. S. (2005). Coordinated Failure? A Cross-Country Bank Failure Prediction Model. Institute Discussion Paper No. 32. http://dx.doi.org/10.2139/ssrn.1905857

Paquet, P. (1997). L'utilisation des réseaux de neurones artificiels en finance. Laboratoire de orléanais de gestion, IAE, wp1997-01, 1-25. Retrieved from http://www.univ-orleans.fr/log/Doc-Rech/Textes-PDF/ 1997-1.pdf

Poghosyan, T., \& Cihak, M. (2011). Distress in European banks: An analysis based on a new dataset. Journal of Financial Services Research, 40(3), 163-184. http://dx.doi.org/10.1007/s10693-011-0103-1

Quagliariello, M. (2009). Stress-testing the Banking System: Methodologies and Applications (pp. 1-336). Cambridge University Press. Retrieved from http://www.cambridge.org/us/academic/subjects/economics/ finance/stress-testing-banking-system-methodologies-and-applications? format $=\mathrm{HB} \#$

Ray, S. (2011). Assessing Corporate Financial Distress in Automobile Industry of India: An Application of Altman's Model. Research Journal of Finance and Accounting, 2(3), 26-43. Retrieved from http://www.iiste.org/Journals/index.php/RJFA/article/view/335

Reinhart, C. M., \& Rogoff, K. S. (2010). Growth in a Time of Debt. American Economic Review, 100(2), 573-578. http://dx.doi.org/10.1257/aer.100.2.573

Sevim, C., Oztekim, A., Bali, O., Gumus, S., \& Gursen, E. (2014). Developing an early warning system to predict currency crises. European Journal of Operational Research, 237(3), 1095-1104. http://dx.doi.org/10. 1016/j.ejor.2014.02.047 
Sinkey, J. F. (1975). A Multivariate Statistical Analysis of the Characteristics of Problem Banks. Journal of Finance, 30, 21-36. http://dx.doi.org/10.2307/2978429

Sorge, M., \& Virolainen, K. (2006). A comparative analysis of macro stress testing methodologies with application to Finland. Journal of Financial Stability, 2(2), 113-151. http://dx.doi.org/10.1016/j.jfs.2005. 07.002

Thomson, J. B. (1991). Predicting Bank Failures in the 1980s. Federal Reserve Bank of Cleveland Economic Review, 27(1), 9-20. Retrieved from http://www.clevelandfed.org/Research/Review/1991/91-q1-thom son.pdf

Vogiazas, S. D., \& Nikolaidou, E. (2011). Investigating the determinants of non performing loans in the Romanian Banking System: An empirical study with reference to the Greek crisis. Economics Research International, 1-13. http://dx.doi.org/10.1155/2011/214689

Wong, J., Choi, K. F., \& Fong, T. (2008). A framework for stress testing bank's credit risk. Journal of Risk Model Validation, 2(1), 3-23. Retrieved from http://www.risk.net/journal-of-risk-model-validation/technical-paper/ 2161266

Wong, J., Wong, T. C., \& Leung, P. (2010). Predicting banking distress in the EMEAP Economies. Journal of Financial Stability, 6, 169-179. http://dx.doi.org/10.1016/j.jfs.2010.01.001

Yildiz, B., \& Akkoc, S. (2010). Bankruptcy Prediction Using Neuro Fuzzy: An Application in Turkish Banks. International Research Journal of Finance and Economics, 60, 114-126. Retrieved from http://nysea.bizland.com/nysea/publications/proceed/2010/Proceed_2010_p143.pdf

\section{Copyrights}

Copyright for this article is retained by the author(s), with first publication rights granted to the journal.

This is an open-access article distributed under the terms and conditions of the Creative Commons Attribution license (http://creativecommons.org/licenses/by/3.0/). 